\title{
A CONFIGURAÇÃO DAS LIVESTREAMS NO CONTEXTO DA PANDEMIA E AS VOZES DA GLOBALIZAÇÃO
}

Configuration of livestreams in the context of pandemia and the voices of globalization

Configuración de livestreams en el contexto de la pandemia y las voces de la globalización

Received: november/2020

Accepted: december $/ 2020$

Available online: december/2020

Joana da Silva Ormundo, Doutora em Linguística, Faculdade de Tecnologia de São Paulo -

FATEC-SP e Universidade Paulista - UNIP, Brasil. E-mail: joana.ormundo@gmail.com

Guilherme Saravalli Jodas Granzotto, Graduado em Análise de Desenvolvimento de Sistema, Faculdade de Tecnologia de São Paulo - FATEC-SP, Brasil, E-mail: gsjgranzotto@gmail.com

Walkyria Wetter, Doutor em Linguística, Universidade Paulista - UNIP, Brasil.

Deborah Gomes de Paula, Doutora em Língua Portuguesa (PUC/SP), UNIP - Universidade Paulista, Brasil. E-mail: deborahpaula@ig.com.br

\footnotetext{
Resumo: Este artigo discute a evolução das livestreams desde o formato televisivo até a forma como esse modelo midiático se configurou na internet. Nosso objetivo consiste em traçar um panorama histórico sobre o processo de constituição das lives nos meios midiáticos e o impacto desse meio nas vozes da globalização. A perspectiva teórica da Análise de Discurso Crítica (FAIRCLOUGH, 2006) fundamentará nosso olhar sobre a forma de constituição das vozes da globalização na constituição das livestreams como mídia de massa. Nosso processo metodológico consistiu em apresentar um percurso sobre os autores da área de tecnologia da informação que apresentam o processo evolutivo das livestreams. Os resultados apontam para a forma como
} 
as livestreams têm impactado as práticas institucionais, marcadas pelas vozes da globalização, no contexto da pandemia.

Palavras-chave : Livestreams, Vozes da Globalização, Interação social.

\begin{abstract}
This article discusses the evolution of livestreams from the television format to the way this mediatic model configures itself on the internet. Our objective is to draw a historical panorama about the process of the constitution of Livestreams in the media and its impacts on the voices of globalization. The theoretical perspective of the critical discourse analysis (FAIRCLOUGH, 2006) will base our view on the form of the constitution of the voices of globalization in the constitution of Livestreams as mass media. The process-methodological bone consisted of presenting a path about the authors of the information technology area that present the evolutionary process of books and interviewed two users of this communication format. The results point to the way in which lives have impacted institutional practices, marked by the voices of globalization, in the context of the pandemic (2020).
\end{abstract}

Keywords: Livestreams; Voices of Globalization; Social interaction.

Resumen: Este artículo analiza la evolución de las transmisiones en vivo desde el formato de televisión hasta la forma en que este modelo de medios se configuró en Internet. Nuestro objetivo es trazar un panorama histórico del proceso de constitución de vidas en los medios y el impacto de este medio en las voces de la globalización. La perspectiva teórica del Análisis Crítico del Discurso (FAIRCLOUGH, 2006) basará nuestra mirada en la forma de la constitución de las voces de la globalización en la constitución de los livestreams como medios de comunicación de masas. Nuestro proceso metodológico consistió en presentar un curso sobre los autores del área de tecnologías de la información que presentan el proceso evolutivo de los livestreams. Los resultados apuntan a la forma en que las transmisiones en vivo han impactado las prácticas institucionales, marcadas por las voces de la globalización, en el contexto de la pandemia.

Palabras clave: Livestreams; Voces de la globalización; Interacción social.

\title{
INTRODUÇÃO
}

Este artigo propõe apresentar uma perspectiva histórica sobre a evolução das Livestreams desde o formato televisivo até a forma como esse modelo midiático se configurou na internet.

Nosso objetivo consiste em traçar um panorama histórico sobre o processo de constituição das lives nos meios midiáticos e o impacto desse meio nas vozes da globalização. Dessa forma, apresentamos como se deu o seu processo de evolução considerando uma abordagem temporal do passado, presente e futuro. Ao tratar do passado, consideramos a forma que ela se configurou na televisão; quanto ao presente, consideramos a 
configuração dessa forma de mídia com o avanço da configuração da sociedade em rede e as novas mídias sociais; e o futuro consiste na forma como as lives impactam ou impactarão as instituições de modo geral.

A perspectiva teórica da Análise de Discurso Crítica (FAIRCLOUGH, 2006) fundamentará nosso olhar sobre a forma de constituição das vozes da globalização na constituição das livestreams como mídia de massa.

Nosso processo metodológico consistiu em apresentar um percurso sobre os autores da área de tecnologia da informação que apresentam o processo evolutivo das lives e realizamos algumas entrevistas e pesquisa, visando obter uma amostragem de como usuários desse modelo midiático entendem o processo de uso desse recurso e o impacto desse modelo midiático na sociedade.

Inicialmente situamos o leitor sobre o contexto atual da pandemia e o avanço desse modelo midiático, a seguir apresentamos a perspectiva teórica da Análise de Discurso Crítica, em seguida apresentamos o percurso histórico sobre o processo evolutivo das lives, e por fim enfatizamos o impacto da mesma nas vozes da globalização e, apresentamos as considerações finais.

\section{Contextualizando o momento atual: pandemia e o uso de lives}

Em dezembro de 2019, veio a público a informação de que uma nova pneumonia estava se espalhando na província de Hubei - China. Logo foi descoberto que se tratava de um vírus da família "Corona”, batizado de Sars-CoV-2, que afetava principalmente morcegos e pangolins na região e acabou se espalhando para seres humanos. Em fevereiro de 2020, 
diversas partes do mundo já tinham sido afetadas e, em março, a Organização Mundial da Saúde (OMS) oficializou que se tratava de uma pandemia.

O primeiro reflexo da pandemia na sociedade veio na forma de uma possível crise nos sistemas de saúde, já que não havia leitos de UTI suficientes para toda a população. Buscando frear o número de casos, diversos países adotaram formas de quarentena ou lockdown e isso trouxe o segundo reflexo, uma recessão econômica global.

Com campanhas para o distanciamento social, muitas empresas precisaram se reinventar, restaurantes tornaram-se dependentes de delivery, escolas reformularam toda a estrutura de ensino para um período $100 \%$ remoto, escritórios adotaram políticas de home-office e alguns setores, como o de turismo e indústria de base, estão à beira do colapso.

Muitos trabalhadores acabaram perdendo emprego e espaço no mercado. Esse fato intensificou ao redor do mundo o debate sobre "Renda Básica Universal", ideia que consiste em um governo pagando um salário aos seus cidadãos como forma de reduzir a miséria e a desigualdade social. Diversos governos deram subsídio econômico aos cidadãos e empresas afetadas pela crise.

Alguns empresários e funcionários perceberam um aumento de produtividade em home-office, o que tem levado a considerar a adotarem permanentemente o trabalho remoto mesmo após o fim da pandemia.

\section{Livestreams como solução em tempos de distanciamento}

Live vem do inglês "Vivo", mas também é usado com o mesmo sentido do "Ao vivo" em português por veículos de notícias e mídias anglófonas, já Stream vem do inglês 
"Corrente/Riacho" e é usado na área de tecnologia em sentido figurado, pois o modo que os dados saem do servidor e passam por outros servidores intermediários até chegarem no roteador e serem exibidos no dispositivo se assemelham conceitualmente à correnteza de um riacho, que sempre guia mais água até o destino de maneira constante. Uma livestream funciona com a combinação desses dois conceitos, uma corrente de dados sendo carregados da máquina do Streamer (aquele que faz a livestream) para a internet para serem baixados em tempo real pela audiência.

Figura 1 - Exemplo do uso do termo "Live" como "Ao vivo" em noticiário durante o atentado de 11 de setembro em Nova Iorque

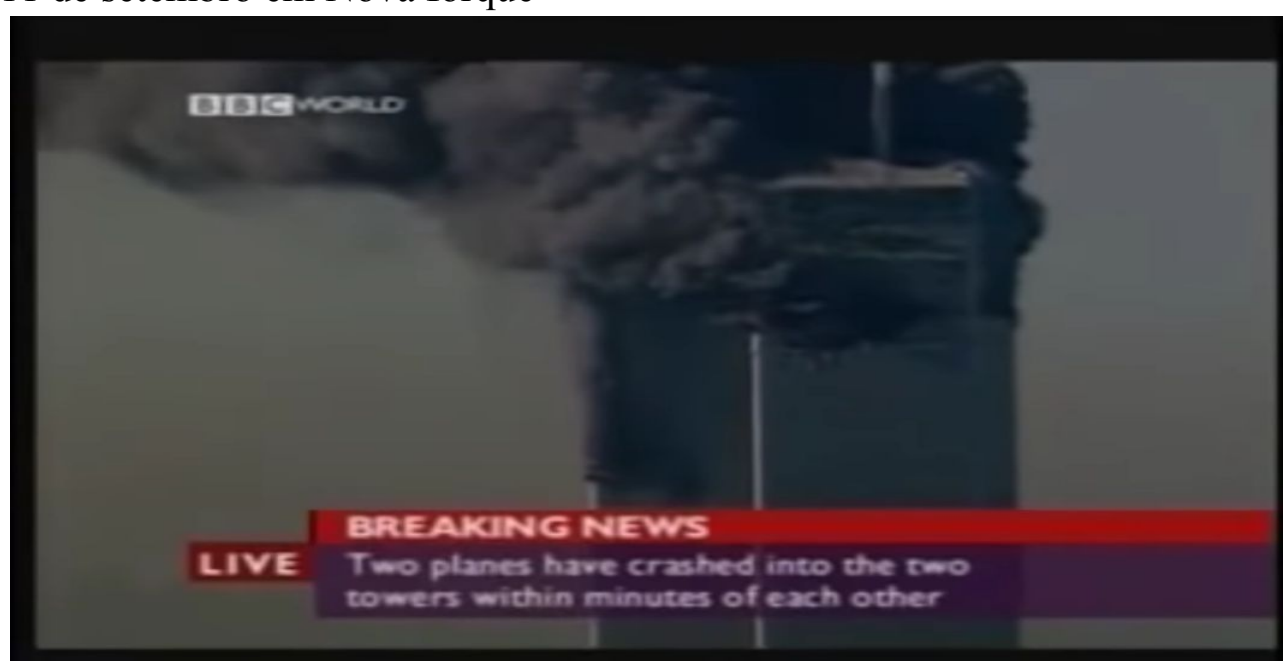

Fonte: primeira transmissão na BBC do Reino Unido, 11/09/2001

Uma livestream é uma exibição ao vivo transmitida pela internet, logo, é seguro afirmar que uma aula à distância, uma videoconferência empresarial, uma partida de um campeonato esportivo e um show musical se enquadram neste modelo midiático.

A quarentena teve um impacto direto no interesse da população por lives. Ao usarmos a ferramenta Trends do Google (https://trends.google.com), que nos permite verificar a periodicidade de uso de como determinado termo é pesquisado, percebemos um aumento 
considerável nas buscas pelo termo Livestream entre os dias 15 e 21 de março a nível global, conforme demonstrado na figura 2:

Figura 2 - Imagem do Google Trends mostrando o interesse de pesquisas do termo 'livestream' nos últimos 12 meses

\section{$\equiv$ Google Trends $\quad$ Pesquisar}

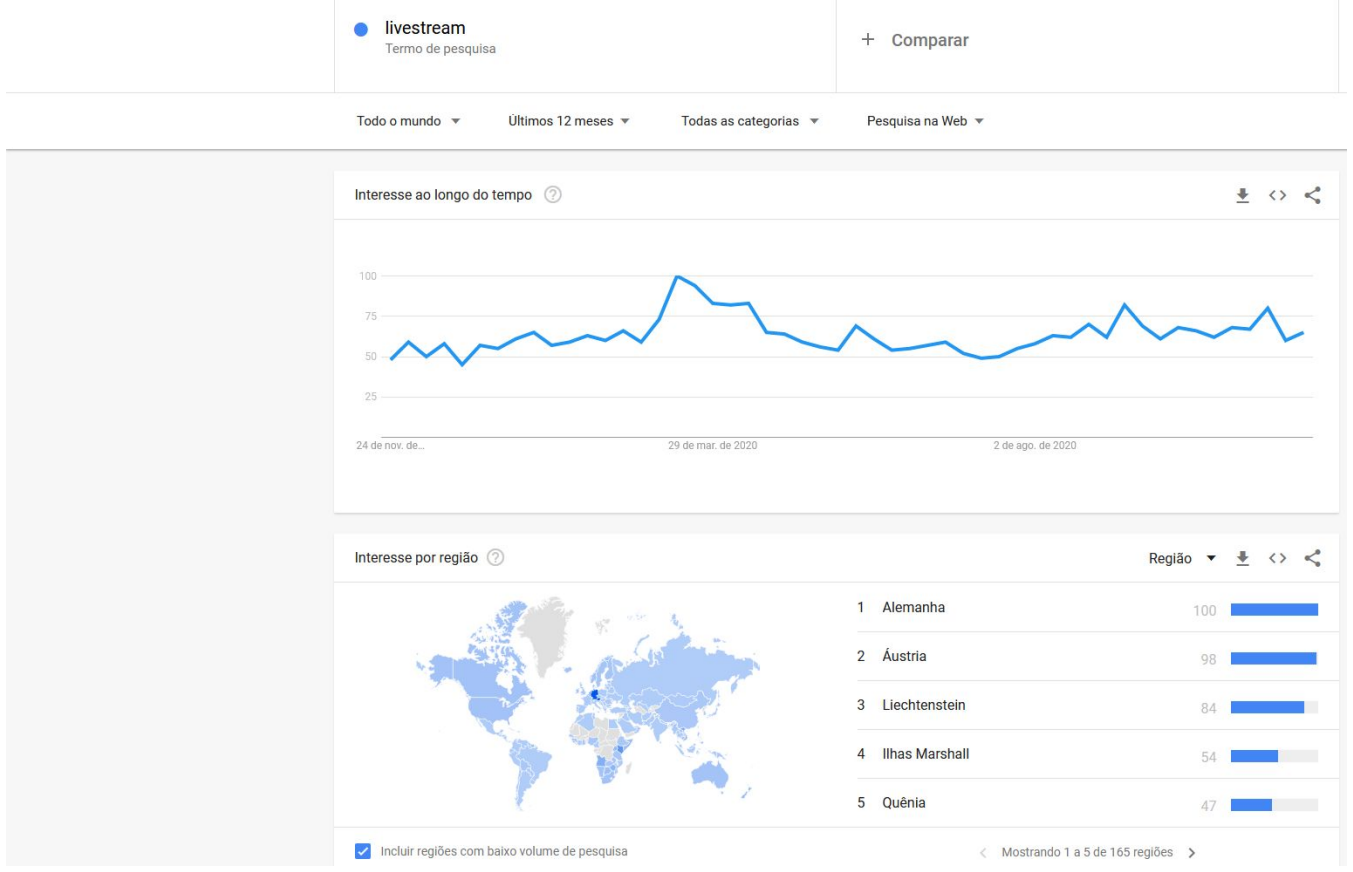

Fonte: Dados da pesquisa.

Com o crescimento da pandemia, diversos eventos de grande porte foram cancelados pelo mundo, tais como shows de música, campeonatos esportivos, congressos de diversas áreas, conferências da indústria do entretenimento, palestras e vestibulares. Eventos corriqueiros também foram afetados, idas ao médico, à restaurantes e a bancos tem sido desestimulada em favor de alternativas com distanciamento social, como delivery e atendimento online.

A maioria desses eventos conseguiu ser substituída com sucesso pelo modelo midiático de livestreams. A comunidade de medicina passou a encorajar mais as "tele 
consultas" que podem ser feitas por telefone ou lives e diversos artistas anunciaram shows gratuitos em plataformas de streaming. Empresas criaram seus próprios eventos ao vivo para fazer anúncios e revelar conteúdo inédito e eventos, tradicionalmente presenciais, foram completamente adaptados para uma realidade de distanciamento social. O poder judiciário brasileiro autorizou o uso desse modelo midiático, durante a pandemia, para julgar casos considerados urgentes e a igreja católica incentivou a capacitação de padres e bispos para conduzir missas em live.

Virtualmente todos os serviços que dependiam unicamente de interação humana, exposição, análise e coleta de dados, tem conseguido sobreviver à crise graças ao uso de lives, entretanto, a sua utilidade das está longe de ser apenas comercial já que, para pessoas em situação de isolamento, ela é uma das únicas formas de contato visual e interação social.

\section{Livestreams e as vozes da globalização}

A perspectiva teórica que orienta nosso olhar para as Livestreams, no contexto atual, fundamenta-se na perspectiva da Análise de Discurso Crítica (ADC), com base na obra Linguagem e Globalização de Norman Fairclough (2006) e na Semiótica Social por meio dos aspectos de representação social discutidos em Van Leeuwen (2005). A escolha teórica considera a pesquisa social no momento da globalização e na forma de representação dos agentes sociais por meio do uso das novas práticas de linguagem que se configuram nesse modelo midiático.

A contribuição da ADC fundamenta-se no que Fairclough (2006) discorre sobre Vozes da Globalização. São elas: análise acadêmica, organizações governamentais, 
organizações não-governamentais, mídia e pessoas comuns. O autor enfatiza a importância da voz da mídia no processo dialético que ocorre conforme demonstrado na figura 3:

Figura 3 - Vozes da Globalização

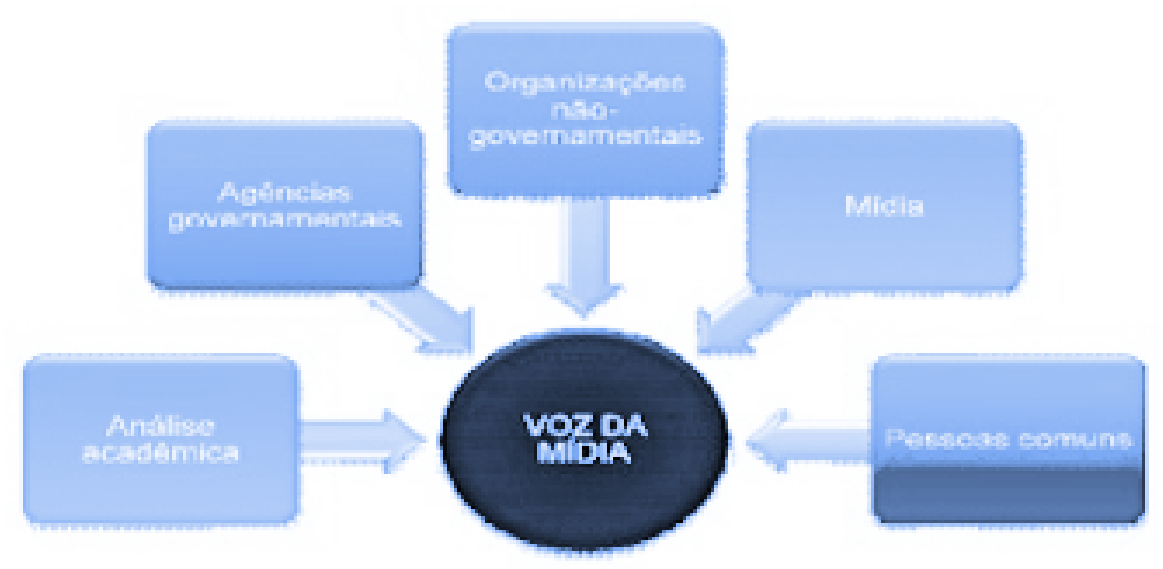

Fonte: ORMUNDO e WETTER, (2013).

É importante destacar, como essas vozes da globalização são impactadas no uso das livestreams e como tem reconfigurado essas práticas institucionais, tais como a implantação desse modelo midiático tanto no ambiente educacional, empresarial, governamental, na vida cotidiana e nas mídias.

Para o autor, essas vozes funcionam como uma espécie de mediação na forma como os agentes sociais são constituídos nas práticas sociais diversas. Fairclough (2006) afirma que as pessoas têm suas próprias experiências da globalização na sua vida comum e nas comunidades em que estão inseridas e reagem, de modo particular e diferente, às experiências que lhes são apresentadas. Dessa forma, apontaremos neste artigo como a pandemia acelerou o consumo das lives, sendo que a tendência dela antes da pandemia já se constituía como forma de ascensão; sendo que o isolamento e as medidas de prevenção 
impostas por agências governamentais e não governamentais durante a pandemia, acelerou esse processo de utilização.

A Análise de Discurso Crítica contribui teoricamente para a compreensão dos processos de transformação e mudança social, visto que possibilita aos agentes sociais o relato de suas experiências e vivências nos locais pesquisados, considerando a dinâmica e a natureza das vozes da globalização. Além disso, esse viés teórico salienta a importância da "voz da mídia", já que todas as outras vozes, para existirem, devem passar por ela e, concomitantemente, a sua relevância no processo de construção dos significados e na produção de representações, elementos esses de extrema importância para o desenvolvimento da conscientização dos sujeitos sobre suas demandas mais prementes. O momento da configuração da live coloca em cena esses agentes sociais que dentro dos seus campos de atuação, conforme a teoria do campo de Pierre Bourdieu, exercem um papel dentro deste recurso midiático, que visa ampliar seu capital simbólico.

Dessa forma, o uso das linguagens nas diversas formas de lives, como uma forma de interação e representação dos sujeitos que utilizam os diversos contextos aqui apontados e, principalmente, no cenário de pandemia configuram o papel da linguagem como uma forma de poder, legitima determinados sujeitos dentro do campo, sendo que as livestreams proporcionam espaço para a atuação e espetacularização desses sujeitos, colocando-os no palco que amplifica sua visibilidade. Saem de um contexto de isolamento social, confinados em suas casas devido a medidas preventivas e se recontextualizam para o mundo, para a sociedade, sendo recolocados no palco, por meio dessa mídia social.

A linguagem, de modo geral, não pode ser pensada sem seu aspecto social, assim, por meio da linguagem, é possível comunicar, organizar e estruturar ideias e pontos de vista de modo significativo. Dessa forma, o uso multimodal das várias formas de linguagens e seus processos de interação social que se configuram nesse modelo são uma forma de 
representação social dos sujeitos dentro do campo midiático das lives e dos seus lugares de fala, ou seja, os lugares institucionais que são representados.

Podemos verificar como o uso dessa nova configuração contribui para dar visibilidade a várias temáticas que se configuram nesse ambiente, sendo determinadas pelo twitch, plataforma de hospedagem de livestreams, por categorias. Essas categorias são apresentadas como jogos, campeonatos ou a categoria "só na conversa" (apenas um bate papo) e no decorrer da pandemia os temas se ampliaram para uso empresarial, institucional, análise acadêmica (escolar), festivais de música, pessoas comuns, por exemplo, usando esse recurso midiático para encontros de família, comemorar aniversários, atividades presenciais tais como Role-Playing Game (RPG) de mesa, conhecidos como jogos de interpretação de papéis, discussões temáticas de literatura, saraus, congressos, eventos diversos que foram recontextualizados para as plataformas de livestreams.

Esse despertar dos sujeitos envolvidos nessas narrativas contadas por este meio midiático pode, inclusive, modificar o comportamento de outras vozes da globalização, como a "voz das organizações governamentais", "a voz das organizações não-governamentais", a "voz da mídia", a "voz da análise acadêmica", e a própria "voz do cidadão comum", despertando a consciência sobre a necessidade de mudança social.

Passaremos para o próximo tópico, apresentando o percurso histórico das lives no campo midiático.

\section{O fenômeno das lives no campo midiático: da televisão à internet}

Conforme aponta Fischer (2017) em seu artigo sobre $A$ invenção da televisão, as primeiras transmissões de televisão foram realizadas na década de 20 no Reino Unido e 
Estados Unidos, mas foi somente no final dos anos 40 e início dos anos 50 que, nos Estados Unidos, as primeiras transmissões ao vivo começaram a ganhar destaque, isso levou a uma popularização do conceito, principalmente na América do Norte, que rapidamente desenvolveu uma cultura repleta de programas ao vivo. A década de 60 trouxe uma explosão de audiência com transmissões lendárias como o assassinato do então presidente John F. Kennedy, as missões Apollo e entrevistas com ativistas dos direitos civis da comunidade afro-americana. Nos anos 70, o conceito de lives já estava bem consolidado na mentalidade ocidental, com incontáveis reality shows, programas de auditório, programas matinais e jornais, sendo esses os campeões de audiência.

$\mathrm{Na}$ entrevista de Zygmunt Bauman para o Fronteiras do Pensamento (2011) há uma citação da frase do sociólogo francês Ehrenberg sobre o início da revolução pós-moderna:

Ehrenberg, sociólogo francês, afirmou que, em sua opinião, a revolução pós-moderna começou numa quarta-feira à noite, num outono da década de 80, quando uma certa Vivienne, uma mulher comum, na presença de 6 milhões de telespectadores, declarou nunca ter tido um orgasmo durante seu casamento porque seu marido, Michel, sofre de ejaculação precoce. O começo da revolução (Transcrição do trecho do vídeo Fronteiras do Pensamento: BAUMAN, 2011).

A entrevista da citação acima foi televisionada. A popularização dessa forma de mídia deve-se, principalmente, a imprevisibilidade das situações, já que não importa o quão ensaiado ou combinado foram as falas e os acontecimentos, eventualmente algo fora do roteiro acontecerá. É por essa razão que Alain Ehrenberg acredita que a televisão ao vivo foi a principal responsável pelo início da "Revolução pós-moderna", uma nova realidade na qual a privacidade é mínima.

A televisão tornou-se a forma de mídia mais consumida do mundo entre os anos $70 \mathrm{e}$ 80, apresentando ao vivo o início e o fim da guerra do Vietnã, a queda do muro de Berlim e o subsequente colapso do bloco soviético. 
No processo de evolução das mídias, marcado pela revolução tecnológica e o avanço da internet, encontramos um fenômeno de ampliação dos meios midiáticos para uma configuração de sociedade em rede o que será tratado a seguir sobre a transição das livestreams para o ambiente da rede de internet.

\section{Configuração da sociedade em rede}

Manuel Castells (1999), em suas obras Sociedade em Rede discorre sobre os processos de configuração da sociedade em rede. O final da década de 60 e início da década de 70 viu o surgimento da arpanet, uma rede de compartilhamento de informações que criou as bases do que viria a ser a atual internet, sendo que nessa época, a arpanet era utilizada para fins acadêmicos e militares e não seria relevante para o público civil até pelo menos a década de 80

A internet popularizou-se rapidamente no mundo inteiro nos anos 90 após a criação do "world wide web”. Uma gama de novos serviços apareceu, serviços como o Napster que funcionava com sistema "peer to peer"/ "par para par” ou P2P. Nesse sistema, um usuário (ou par) faz o upload de um arquivo para o servidor, cada usuário que fizer o download deste arquivo também fará o upload para outros eventuais pares.

Figura 3 - Exemplo visual de como um sistema P2P opera. 


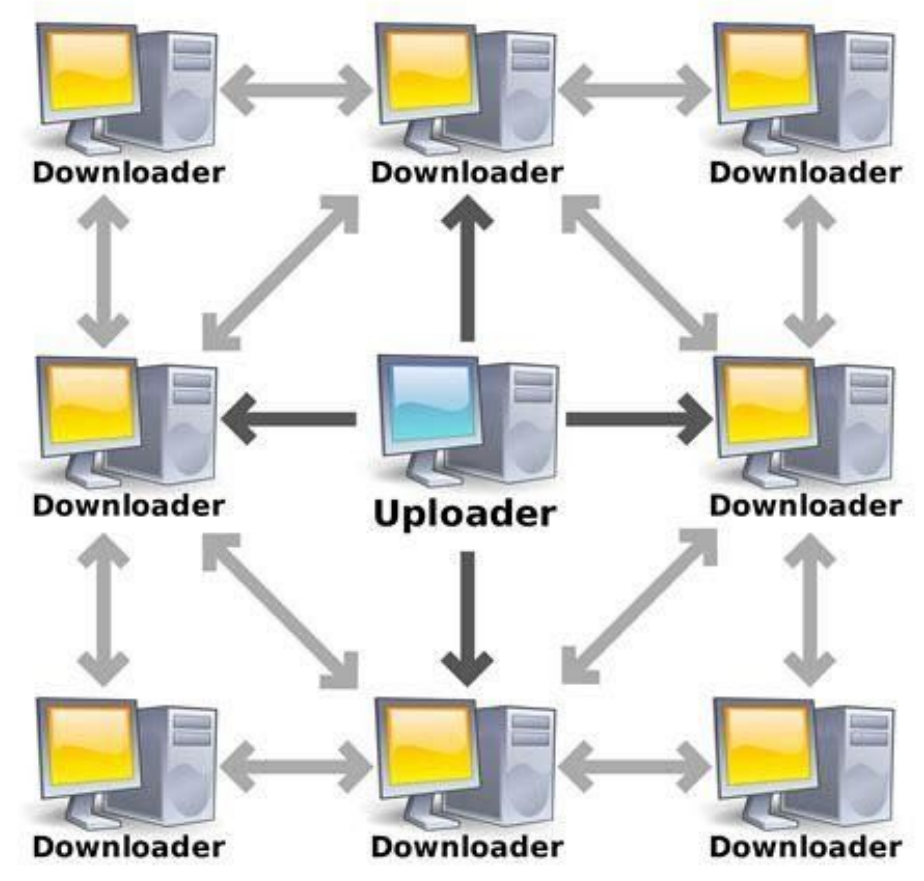

Fonte: EDTECHCHRIS, (2020).

O problema desses serviços era que muitos dos arquivos compartilhados violavam leis de direito autoral. Em 1998, o "Ato de direitos autorais do milênio digital”, ou DCMA, foi aprovado pelo governo dos Estados Unidos. Esse fato e a existência de uma bolha no mercado de tecnologia fizeram o ano 2000 ver uma crise pesada no setor, investimentos caíram, muitos negócios fecharam as portas e empresas como o Napster sofreram diversos processos judiciais.

Porém, mesmo com diversas empresas indo à falência, novas tecnologias continuavam surgindo, uma delas era o RTP, "real-time transfer protocol”. Ao contrário de outros protocolos para download, o RTP focava em dar acesso ao conteúdo durante o download dos arquivos. Eventualmente, foi possível mesclar os protocolos RTP e P2P, usando o princípio de upload pulverizado em várias máquinas e o acesso on demand, pouco tempo depois, essa mescla foi adaptada a tecnologia de HTTP, que permitia fazer tudo isso diretamente pelo 
navegador, isso viabilizou sites de vídeos on demand como o "YouTube" que surgiu como forma de compartilhar vídeos maiores do que era permitido nos e-mails entre amigos.

O cerco contra a pirataria fez empresas apostarem em serviços dentro da lei para streaming, um dos mais proeminentes foi o iTunes, da Apple, que usava a mesma tecnologia do Napster para vender músicas licenciadas pelas gravadoras ao invés de deixar que cada usuário fizesse um upload.

Perto do fim da década de 2000, a computação em nuvem passou a ser cada vez mais eficiente e popular, isso acabou gerando a criação de redes sociais complexas e dos primeiros serviços de streaming online. Agora, qualquer pessoa com uma internet suficientemente rápida e uma máquina razoável poderia se apresentar ao vivo na web, algo que seria impensável na televisão.

A Twitch, uma das maiores plataformas de streaming do mundo, foi fundada em 2011, utilizando os protocolos HTTP-RTP-P2P como base. Concebida inicialmente para a transmissão de campeonatos de e-sports e gameplays, sendo uma das principais responsáveis pela popularização do setor de livestreams, tendo um crescimento de vinte milhões de usuários ao mês em 2012. Embora o foco continue sendo o público gamer, é possível encontrar podcasts, música e tutoriais ao vivo no site, conforme aponta Burroughs (2015).

\section{O uso das mídias sociais antes da pandemia}

A maioria das redes sociais, como as do grupo Facebook e o YouTube, passaram a contar com um modo livestream, antes da pandemia, muitas vezes chegando a fechar contratos de exclusividade com influenciadores para que utilizem o recurso em apenas uma plataforma. A gigante Amazon comprou a Twitch por quase um bilhão de dólares em 2014, vencendo a corrida contra a Microsoft. Em 2019, a plataforma contava com mais de três 
milhões de streamers mensais. O mercado de jogos eletrônicos foi profundamente mudado por este modelo midiático, sendo difícil imaginar que, no começo da década de 2010, grandes desenvolvedoras de jogos dificultavam ao máximo lives de seus produtos, por vezes até mesmo censurando o conteúdo criado. Essa tendência só foi revertida graças ao sucesso dos “indie games”, jogos criados por desenvolvedores amadores ou estúdios pequenos e que incentivavam a comunidade streamer a criar conteúdo, isso levou a uma explosão de popularidade e vendas de jogos vistos como "simples" e sem um grande orçamento por trás.

O jogo mais vendido da história, Minecraft, tornou-se imensamente popular pela quantidade de conteúdo criado pela comunidade desde seu lançamento em 2009. O mercado percebeu que este modelo midiático é uma excelente fonte de marketing, e empresas que antes brigavam com criadores de conteúdo passaram a presenteá-los com seus lançamentos de graça apenas para que fizessem lives jogando-os.

O impacto foi tão forte nessa indústria que ajudou na criação e consolidação de um novo gênero de jogos: o battle royalle, gênero em que um jogador ou esquadrão de jogadores lutam contra outros num mapa que fica cada vez menor, vence o último jogador ou esquadrão de pé. O battle royale surgiu com uma modificação do jogo de guerra "Arma 2", chamada de "DayZ mod", a modificação adicionava zumbis e os jogadores, na pele de sobreviventes, tinham que lutar entre si por recursos para atingir a vitória, o jogo se tornou popular com livestreams, que criavam memes e situações cômicas ou de tensão. Eventualmente a equipe desenvolveu um jogo independente de "Arma 2" chamado "DayZ StandAlone", mas o gênero tornou-se mundialmente popular com o game "Player Unknown's Battlegrounds", ou PUBG, como é chamado pela comunidade, não tinha zumbis e focava no combate e coleta de recursos entre players. O jogo tornou-se tão bem-sucedido comercialmente que diversas empresas seguiram a tendência, a franquia bilionária "Call of Duty", da gigante Activision, ganhou um modo "Battle Royalle" gratuito, o jogo "Hyper Scape", da também 
gigante Ubisoft, foi lançado em 2020 com foco em livestreams, desenvolvido desde 2018, o mapa do jogo pode mudar de acordo com votos de quem está acompanhando a partida ao vivo, conforme apontam Johnson \& Woodcock (2018).

\section{Livestreams e a relação com o mercado no contexto da pandemia}

Neste tópico, apresentaremos como reflete o fenômeno das Livestreams na relação com o mercado comercial e a expectativa futura no contexto da pandemia. Com base em dados publicados no blog Neipatel $^{2}$ sobre a importância das live streaming, estima-se que em 2021, a indústria de streaming seja de 70 bilhões de dólares, esse valor, que inclui anúncios, inscrições premium e doações, é mais que o dobro do valor registrado em 2016 de 30 bilhões de dólares. Também é estimado que este meio midiático seja responsável por $82 \%$ de todo o tráfego de dados da internet em 2020, conforme dados apontados no site go-globe que apresenta estatísticas atualizadas sobre livestreams.

Desse modo a twitch, maior plataforma com base em horas assistidas, tem atualmente cerca de 6.5 milhões de streamers mensais e a audiência de e-sports tende a chegar em 84 milhões em 2021, menos de 18 milhões a menos que a audiência do Super Bowl de 2020, final mais importante do futebol americano. A empresa está confiante em bater a marca de 1

\footnotetext{
${ }^{2}$ Os dados estatísticos apresentados foram acessados na semana de 12 a 19 de novembro de 2020 e tiveram como fonte os seguintes sites: https://neilpatel.com/blog/live-streaming-importance-2018/; https://twitchtracker.com/statistics; https://onlinegrad.syracuse.edu/blog/esports-to-compete-with-traditional-sports/; https://variety.com/2020/tv/news/super-bowl-liv-ratings-1203490564/; https://www.datanyze.com/market-share/live-streaming--71/twitch-market-share; https://livestream.com/blog/live-video-statistics-livestream
} 
bilhão de dólares em receita no ano de 2020 mesmo tendo apenas $2.72 \%$ do market share total da indústria.

Segundo dados divulgados pelo serviço "livestream.com" cerca de $67 \%$ da audiência que vivenciou uma experiência em lives buscou reproduzir essa experiência pessoalmente. Segundo Neil Pattel, 60\% dos usuários fazem pesquisa enquanto assistem lives, comparado com 48\% que pesquisam enquanto assistem $\mathrm{TV}$, isso é uma vantagem não apenas para fact-checkers mas também para anunciantes, pois não é necessário investir muito dinheiro em propagandas para chamar a atenção, basta apenas ser citado para que uma parte da audiência procure por conta própria. Isso está revolucionando a maneira de fazer marketing na internet, já que empresas buscam maneiras menos intrusivas de anunciar, apostando na curiosidade do usuário, cortando custos e aumentando a exposição da marca.

Como já mencionado neste artigo, a indústria dos games foi uma das primeiras a precisar adaptar-se devido ao impacto desse novo recurso midiático. Alguns jogos são desenvolvidos, especificamente, para e-sports e geração de conteúdo em livestream. A Disney e a ESPN compraram direitos de exibição para campeonatos de Overwatch $^{3}$, que agora também serão vistos em seus canais e plataformas além de outros meios mais tradicionais como Twitch e YouTube. A figura 4 ilustra o streamer e ex-jogador profissional de Counter Strike, Gaules, bateu o recorde de maior número simultâneo de espectadores numa livestream

${ }^{3}$ Informação disponível em:

https://www.espn.com/esports/story/_id/24062274/overwatch-league-comes-espn-disney-abc 
em português, com 393,263 pessoas assistindo ao vivo. ${ }^{4}$ Ele também foi o segundo canal mais assistido da Twitch do mundo em horas totais no primeiro semestre de $2020^{5}$

Figura 4 - Foto do streamer e ex-jogador profissional de Counter Strike, Gaules.

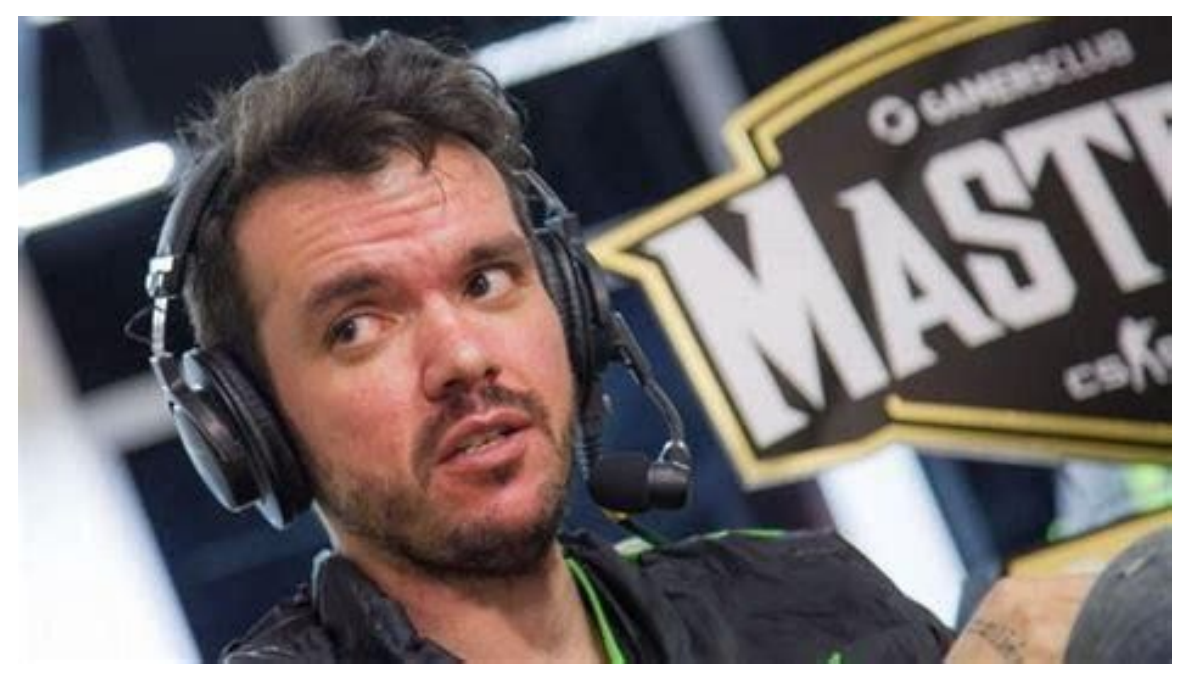

Fonte: $\operatorname{ESPN}(2020)$.

Em relação ao facebook, a média de tempo visto em conteúdo do Facebook Live é três vezes maior que vídeos que não são ao vivo na plataforma. As Livestreams já eram o “mercado do futuro" desde 2014, mas foi em 2020, com a pandemia de Covid-19, que essa indústria se tornou o mercado do presente com uma influência cada vez maior na sociedade e valores de ações subindo a cada dia. Em setembro de 2020, o Zoom, serviço de reuniões em streaming, passou a ter mais valor de mercado que a tradicional IBM. Essa tendência de subida do Zoom, desde o começo da pandemia, acabou criando uma curiosidade: uma fábrica de produtos para celulares chamada "Zoom Technologies" teve seu valor de mercado

\footnotetext{
${ }^{4}$ Informação disponível em: https://globoesporte.globo.com/e-sportv/csgo/noticia/csgo-gaules-quebra-recorde-de-espectadores-simultaneos-n a-twitch.ghtml

${ }^{5}$ Informação disponível em: https://www.esportznetwork.com/top-10-most-watched-twitch-streamers-in-2020/.
} 
triplicado em março, pois investidores estavam confundindo-a com a "Zoom Video" na hora de investir. ${ }^{6}$

\section{Livestreams como um novo meio de comunicação de massa}

Esse fenômeno midiático estaria se configurando como um novo meio de comunicação de massa? Esse é um questionamento que colocamos para reflexão sobre como esse formato midiático tende a se configurar na sociedade. Se entendemos que a mídia de massa é, por definição, uma forma de mídia que consegue atingir uma grande parcela da população e também tem um alto poder de influência na sociedade, especificamente na sociedade de consumo, algumas estatísticas da indústria de livestreams revelam que, se ainda não puder se enquadrar como mídia de massa, está cada dia mais próximo disso. As lives têm diferenças fundamentais para a televisão, rádio e outras formas de mídias de massa tradicionais: não possuem um dono e o modo de interação é diferente. Assim, muitos canais de TV, no mundo inteiro, são fundados ou comprados e mantêm-se na mesma família a gerações. É inevitável, nesses casos, que as visões do proprietário afetem o modo em que a informação é passada para a população.

A internet não surgiu para quebrar monopólios de informação. Isso foi uma consequência do imenso fluxo de dados pela internet entre pessoas, mídias que falham em se adaptar a essa nova realidade e acabam perdendo espaço de mercado. Entretanto, isso também

6https://einvestidor.estadao.com.br/mercado/home-office-valoriza-zoom-investidorescompram-acoes-err adas-e-bolsa-suspende-venda-de-empresa-homonima/. 
tem seu lado negativo, como normalmente o anunciante paga por cliques, muitos sites se especializaram em sensacionalizar ao máximo o título para atrair mais cliques, essa técnica acaba favorecendo mais o clique de um usuário casual, mas acaba por evitar a fidelização a longo-prazo.

Embora, notícias falsas sempre tenham existido na história, o fenômeno das Fake News ganhou muita notoriedade pela facilidade em espalhar notícias falsas ou apenas meio verdadeiras. Muitas delas usam a tática de sensacionalizar ao máximo para atrair mais leitores e, além disso, ainda sensacionalizam o resto do conteúdo para parecer que o título não era tão sensacionalista quanto parecia.

Para interagir verdadeiramente com um programa ao vivo na televisão é preciso ligar para um telefone, mandar um e-mail ou estar fisicamente no local da gravação. Enquanto nas livestreams basta apenas fazer comentários ao usar o chat. No que se diz respeito a interações, lives são muito mais "de massa” do que qualquer outra mídia já que um streamer pode ver em tempo real a reação de sua audiência.

Esse jeito mais "democrático" e focalizado desse novo meio midiático faz com que anunciantes possam aumentar o alcance de seus serviços. A televisão tem uma penetração social maior, mas a porcentagem da audiência que deseja um produto em específico é muito pequena. As livestreams, mesmo quando tem uma audiência menor que a de um grande canal de televisão, têm espectadores muito mais engajados e interessados em produtos relacionados ao tema da live.

\section{Vozes da globalização: o papel das livestreams no ensino remoto e o impacto nas instituições}


Com o impacto da pandemia na sociedade, muitas práticas sociais foram reconfiguradas. O impacto no ensino e em instituições públicas e privadas desencadeou uma reestruturação dos papéis sociais e das ordens do discurso por meio dos processos de produção, circulação e consumo de mercadorias, saberes e práticas discursivas. Esse impacto no sistema educacional ressignificou muitas práticas. $O$ ensino presencial foi reconfigurando-se em ensino remoto, em que professores, alunos e instituições tiveram que repensar suas formas de interação, produção e circulação de conteúdo, de transmissão da informação e construção do conhecimento. E, nesse contexto, as livestreams tiveram um papel relevante para viabilizar que o processo educacional prosseguisse. Há duas possibilidades de se realizar um curso remoto. A primeira opção, consiste na possibilidade de substituir o professor por materiais de referência e adaptar o professor para transformar sua aula em uma livestream. A segunda opção foi a adotada pela Faculdade de Tecnologia de São Paulo FATEC-SP nos períodos de ensino remoto, que contou com períodos de capacitação de alunos e professores para o Microsoft Teams, a plataforma escolhida pela Instituição Educacional.

Além da utilidade para professores transmitirem o conteúdo de suas aulas, esse recurso midiático também se tornou uma solução para estudantes debaterem trabalhos e atividades em grupo de maneira organizada. Outra ferramenta muito utilizada tanto para o ensino remoto quanto para reuniões de trabalho é o Zoom Video e o Skype. O último possuindo a versão for business como solução oficial para ambientes empresariais.

O mercado de trabalho tem muito para se beneficiar do uso desse novo recurso midiático, sendo que muitos dos seus processos de produção podem ser realizados remotamente, bem como diversas partes do dia a dia, principalmente reuniões que poderiam ser encurtadas e simplificadas sem uma alteração grande de esforço para realizá-las. O 
impacto dessa nova configuração tanto no ambiente escolar como no ambiente empresarial será algo a ser acompanhado no decorrer da evolução das práticas sociais futuras.

\section{Considerações Finais}

Com base no que foi discutido até o momento, pode-se entender que mesmo antes da quarentena a indústria de livestream já vinha crescendo. A situação do distanciamento social atual só acelerou essa tendência. Poucas pessoas poderiam prever que a maior indústria do entretenimento, como a dos games, seria influenciada por uma numericamente inferior em termos de receita. É esperado que a indústria de livestreams tenha um valor de mercado de 70 bilhões de dólares em $2021^{7}$, para comparação, em 2018 a indústria cinematográfica faturou mais de 40 bilhões de dólares em bilheteria ${ }^{8}$. Livestream é um formato midiático que, ao que tudo indica, veio para ficar e, com a democratização da internet, eventualmente se torna uma forma tão dominante de mídia quanto a televisão no auge das décadas de 70 e 80 .

O futuro parece ser muito promissor para o streaming, tanto como formato midiático quanto uma ferramenta auxiliar em diversas áreas. Com uma base crescente de usuários e uma valorização de mercado vibrante, é difícil pensar que não estejamos tratando de uma mídia do futuro que cada vez mais ganha espaço no presente.

\section{REFERÊNCIAS}

BAUER, W.; GASKELL, G.. Pesquisa qualitativa com texto, imagem e som: um manual prático. Tradução de Pedrinho a. Guareschi. 4ª Ed. Petrópolis, Vozes, 2005.

\footnotetext{
${ }^{7}$ https://neilpatel.com/blog/live-streaming-importance-2018/;

8.https://www.bol.uol.com.br/entretenimento/2019/03/22/industria-cinematografica-registra-lucro-record e-em-2018.htm
}

RBPPD/BRJPD | Vol. 2 | n. 4 | p. 24-46, 2020. 
BAUMAN, Z. Fronteiras do Pensamento, 2011. Disponível em:

http://www.fronteiras.com/en/videos/dialogos-com-zygmunt-bauman. Acessado em: $12 / 11 / 2020$ às $18 \mathrm{~h}$.

BURROUGHS, B. E.. Streaming media: audience and industry shifts in a networked society. (2015). DOI 10.17077/etd.e9qi86xf. Disponível em:

https://ir.uiowa.edu/cgi/viewcontent.cgi?article=5890\&context=etd. Acessado em 19/11/2020 às $21 \mathrm{~h}$.

CASTELLS, M. A Sociedade em Rede.Volume I. São Paulo: Ed Paz e Terra. 2003.

EDTECHCHRIS. Support Apple Classroom without Opening the Network for Peer to Peer Traffic. Disponível em:

http://edtechchris.com/2016/08/02/support-apple-classroom-without-opening-network-peer-p eer-traffic/. Acessado em 19/11/2020 às $21 \mathrm{~h}$.

FAIRCLOUGH,N. Critical discourse analysis in researching language in the new capitalism: overdetermination, transdisciplinarity and textual analysis. Lancaster, 2003b. 2006.

FAIRCLOUGH, N. Language and Globalization. London; New York; Routledge,

FISHER, D. E. The invention of television. Disponível em: https://www.britannica.com/technology/television-technology.Acessado em: 19/11/2020 às $20 \mathrm{~h}$.

JOHNSON, M. R.; WOODCOCK, J.. The impacts of live streaming and Twitch.Tv on the video game industry, Media, Culture \& Society, v. 41, n. 5, p. 670-688, 2019.

KRESS, G.; VAN LEEUWEN, T. The Grammar of visual design. Routledge Taylor Francis Group. London: 2006.

LI, BAOCHUN et al. Two decades of internet video streaming: A retrospective view. ACM transactions on multimedia computing, communications, and applications (TOMM), v. 9, n. 1s, p. 1-20, 2013.Disponível $\mathrm{em}$ : https://iqua.ece.toronto.edu/papers/bli-tomccap13.pdf . Acesso em: 10/11/2020 às 16h.

McCOWN, F.. A short history of the internet and web (narrated). Disponível em: https://sites.harding.edu/fmccown/history-of-internet-and-web.pdf. Acessado em $10 / 11 / 2020$ às $20 \mathrm{~h}$.

ORMUNDO, J.; WETTER,W. Práticas de linguagem na globalização: Introdução à análise de discurso crítica em uma perspectiva transdisciplinar. São Paulo: Patuá, 2013. 
